\title{
Rotational Grazing and the Profession and Practice of Rangeland Management
}

\section{By Joel Brown and Mort Kothmann}

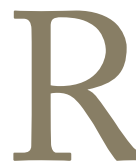

otational grazing systems and the research upon which they are based are an integral part of the profession of rangeland management, both the science and the art. A quick overview of the literature shows how frequently rotational grazing is referred to in the two primary journals of the Society for Range Management. Using the search engine associated with the archives of Rangelands from 1979-2003 and searching for "rotation grazing" returned 252 articles with those words in the title or keyword list. The use of the phrase "grazing system" returned 718 articles with those words in the keywords or title. About 1,500 articles were published over this period.

Likewise, a search of the Journal of Range Management archives from 1948-2003ii showed a similar emphasis. The search phrase "grazing system" returned 1,513 articles, and "rotation grazing" returned 645 relevant articles. There were approximately 5,500 articles published in $J R M$ over this period. While these are not in-depth analyses by any means, they are a good indication of the emphasis that has been placed on a systematic approach to grazing management over the history of our profession.

In a recent paper, Briske et al. ${ }^{1}$ ignited a controversy with their conclusions that rotational grazing (in various forms) was not superior to continuous grazing when the metrics of interest were plant or livestock production. Their review cited 47 experiments varying from 2 years to $>25$ years in length conducted and published over the past six decades. Although they were hardly the first to question the effectiveness of rotational grazing in stimulating plant or livestock productivity, ${ }^{2-4}$ many have disagreed with these findings. That disagreement has been expressed among the ranchers who employ one of many forms of rotational grazing, advisors and consultants who have promoted and

\footnotetext{
See Rangelands archive at: https://www.uair.arizona.edu/holdings/ journal?r=http://rangelands.library.arizona.edu/

ii See Journal of Range Management archive at: https://www.uair. arizona.edu/holdings/journal?r=http://jrm.library.arizona.edu/
}

assisted in the implementation of grazing systems, administrators who have incentivized grazing systems with public resources, and researchers who have investigated and observed grazing systems. This controversy should not be downplayed. Quite the contrary, this is how science and professions advance. A group of researchers states a welldefined hypothesis, examines the relevant experimental literature, and rejects that hypothesis and proposes alternative explanations. We believe that the challenge now before us is not to refute or reject the findings of Briske et al. (although that is certainly a possibility), but to take those findings and construct new hypotheses to explain the observations and to test them with broadly accepted and credible designs and methodologies.

The challenges associated with developing those tests are substantial and should not be lightly regarded. First, research often lacks immediate application, if not overall relevance, to issues of interest to managers. In their attempts to isolate and evaluate a narrow range of important biophysical drivers, researchers can confuse or lose the connection to real-world management decisions. Although the ecological processes investigated may be critical, they can be several steps removed from those that field practitioners observe and measure, and they can appear to have only minimal connection to commercial-scale decision making. By controlling variability, whether through the use of a growth chamber, glasshouse, common garden, small plots, or experimental fields, researchers run the risk of becoming irrelevant to the most important processes in management: adaptation and change. In fact, Briske et al. ${ }^{1}$ explicitly cited three areas (i.e., conservation goals, human dimensions, and spatiotemporal scale effects) largely excluded from the experimental design in the studies they reviewed.

On the other hand, practitioners can develop exceedingly creative solutions to seemingly insurmountable problems. However, because they seldom quantify existing conditions and protocols associated with implementation, the ability to communicate the principles of "how to" to other practitioners, advisors, and researchers can be very poor and can 


\section{A parable about ranchers and scientists}

Two ranchers went out for a balloon ride one day. A strong wind arose and blew them way off course. They had to use all of their skills and a little bit of luck to survive the wind storm and land the balloon safely. As they were about to finally touch down, they spotted a couple of scientists collecting field data. "Hey, where are we?" the ranchers yelled out. "In a rainbow-striped balloon, about 20 feet off the ground, descending at a rate of 5 feet per second," the scientists quickly yelled back. Moral of the story: the scientists were exceedingly precise, but not particularly helpful. The ranchers were as happy as they could be, but they still had no idea where they were.

wind up being little more than enthusiastic opinions. An emerging body of literature on the sociology of natural resource management identifies time and changes in spatial scale as powerful confounding forces in the perceptions of landowners in relation to resource conditions and factors driving change. This subsequently diminishes their ability to interpret their observations and to reconcile their opinions with overwhelming evidence to the contrary. ${ }^{5,6}$ Testimonials will only go so far in convincing even mild skeptics.

Our hope in organizing and editing this special issue of Rangelands is not, as we said earlier, to refute or rebut the findings of Briske et al. ${ }^{1}$ and the substantial literature upon which it was based, but to provide explanations that may provide some insight into reconciling the conflicting views associated with their implementation and, most importantly, to identify new approaches to evaluation (both managerial and experimental). This series of papers is unlikely to reconcile opposing views about the effectiveness of grazing systems as a tool to achieve vegetation and livestock objectives. Only well-designed, well-implemented, and well-analyzed research can do that. That research may be done at a variety of scales and through the collection of both traditional and nontraditional data, but it will be good science. No amount of passion will overcome evidence.

\section{Acknowledgments}

Each of the papers in this special issue has been peer reviewed. We would like to thank the following people for their time and effort in providing peer review and constructive comment on these papers: Derek Bailey, Chad Boyd, Justin Derner, Sam Fuhlendorf, Mel George, Wendell Gilgert, Jon Gustafson, Richard King, Jeremy Maestas, Dan Nosal, Rex Pieper, Larry Rittenhouse, Kim Stine, John Tanaka, Lance Vermeire, and John Walker. Their contributions improved the quality of this issue and are greatly appreciated.

\section{References}

1. Briske, D. D., J. D. Derner, J. R. Brown, S. D. Fuhlendorf, W. R. Teague, K. M. Havstad, R. L. Gillen, A. J. Ash, and W. D. Willms. 2008. Rotational grazing on rangelands: reconciliation of perception and experimental evidence. Rangeland Ecology and Management 61:3-17.

2. Heady, H. F. 1961. Continuous vs. specialized grazing systems: a review and application to California annual type. Journal of Range Management 14:182-193.

3. Holocheк, J. L., H. Gomez, F. Molinar, and D. Galt. 1999. Grazing studies: what have we learned? Rangelands 21:12-16.

4. McNaughton, S. J. 1993. Grasses and grazers, science and management. Ecological Applications 3:17-20.

5. Anderson, D. H., and P. J. Jakes. 2004. Landowner perceptions of ecosystem health in upper great lakes states riparian landscapes. Cooperative Park Studies Program. University of Minnesota. Available at: http://cpsp.cfans.umn.edu/Research/ Riparian00.htm. Accessed 2 October 2009.

6. Tibby, J., M. B. Lane, and P. A. Gell. 2008. Local knowledge and environmental management: a cautionary tale from Lake Ainsworth, New South Wales, Australia. Environmental Conservation 34:334-341.

Authors are Rangeland Management Specialist, USDA Natural Resources Conservation Service, Jornada Experimental Range, Las Cruces, NM 88003, USA, joelbrow@nmsu.edu (Brown); and Professor, Dept of Ecosystem Science and Management, Texas A\&M University, College Station, TX 77843, USA (Kothmann). 